\title{
Experimental comparison of a matrix converter using Si IGBT and SiC MOSFETs
}

\begin{abstract}
This paper presents an analytical and experimental comparison between comparable Silicon (Si) IGBTs and Silicon Carbide (SiC) MOSFETS when used in a direct AC/AC matrix converter circuit. The switching performance of the two devices is analysed and the efficiency / losses measured in order to develop a loss model which will help engineers to design and develop matrix converter circuits using these types of devices. Particular attention is given in the paper to the discrepancies found between the data-sheet values and the measured data. The EMI performance of the two matrix converters is also determined and the implication of using high speed devices from both an EMI and an efficiency point of view is formulated together with an improved input filter design.
\end{abstract}

\section{1-Introduction:}

The direct Matrix Converter (MC) [1] topology, as depicted in Figure 1, offers a direct AC-AC, bi-directional power converter solution. This circuit has recently undergone renewed attention, especially in the field of variable speed drive applications [2-5] and in those applications where a more compact and robust solution [6] is required in place of the traditional two-level, rectifier/voltage source inverter (VSI) circuit [7-9]. Many examples in the literature also show the proposed use of the matrix converter technology for aerospace applications [10-13] because it results to a lighter and more power dense power converter implementation with a higher degree of reliability [14] when compared to a back-to-back converter where large DC-link electrolytic capacitors are often used.

The choice of power devices to be used in the realisation of matrix converters has also received recent attention due to the potential advantages that wide bandgap semiconductors could offer. These advantages include faster switching times and potentially lower losses. In [15] a comparison with the use of Silicon Carbide (SiC) schottky diodes in place of the traditional Silicon (Si) PN junction diodes within the matrix converter power circuit was performed in order to determine the benefit in switching losses of reducing the reverse recovery of the diode and turn on losses of the IGBTs. Recent work [16] has also further highlighted the potential of MC technology by replacing the well-established matrix of Si IGBTs and diodes in a bidirectional arrangement with a matrix of SiC JFET devices. In that work it was demonstrated that the use of fast switching power devices allows a considerable reduction in the overall volume of the power converter passive components as well as the importance of an appropriate layout of the power circuit in order to limit EMI issues and device stress, which can both result from high switching speeds. From a power device point of view extensive studies in [17] have been conducted to evaluate the switching performance of all $\mathrm{Si}$, combined $\mathrm{Si}-\mathrm{SiC}$ arrangements and all $\mathrm{SiC}$ commutation cells together with potential routes to the adoption of $\mathrm{SiC}$ technologies.

In order to fully understand the advantages, draw backs and trade-offs when using either Si power devices or $\mathrm{SiC}$ power devices in a direct matrix converter structure this paper proposes an analysis, supported by both a theoretical discussion and experimental validation, of the switching performance of a direct matrix converter. Two 3x3 matrix converters, one constructed using Si IGBTs and diodes and a second one made of $\mathrm{SiC}$ MOSFETs have been built and compared in terms of switching losses and efficiency as well as in terms of Electro Magnetic Interference (EMI) and how this affects the required filter design. The implication of the package size, commutation technique and modulation strategy on the analysis conducted are described in this paper together with practical circuit layout and hence commutation loop inductance. The impact of this inductance on switching times is analysed with regard to switching loses. The practical results obtained point to a significant discrepancy between data-sheet values and practical measurement which makes the power converter designer's job even more difficult, so the reasons for these discrepancies are discussed and analysed. The conclusions drawn will also highlight how this paper contributes to an accurate loss model based on measurements and which takes the practical circuit issues into account in order to modify and correct the datasheet values as these quantities are based on different test circuits and layouts. 


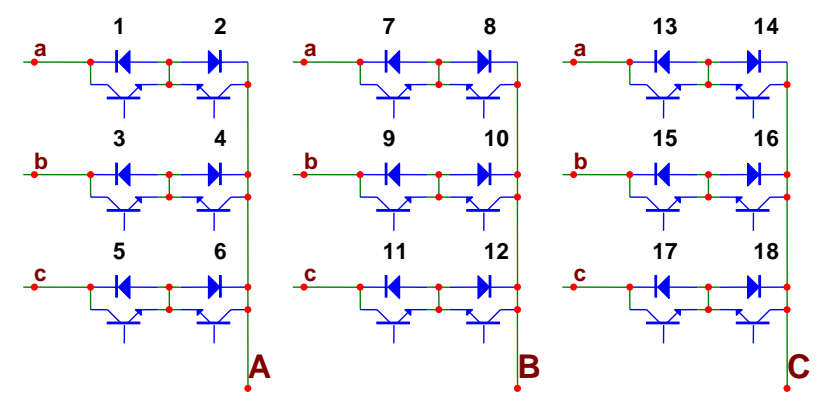

Fig. 1. The matrix converter, where a,b,c are the input phases and A,B,C are the output phases

\section{2-The experimental converter system}

Figure 2 describes the system configuration which has been implemented to determine the differences between Silicon IGBT's and Silicon Carbide MOSFET switching devices in terms of efficiency, switching performance and EMI behaviour. The block diagram of the full system includes: the input filter for the matrix converter for both differential and common mode, an output filter and the resistive load $\left(\mathrm{R}_{\mathrm{L}}\right)$. It also shows the location of the two power analysers that were used to measure the efficiency of the converters (including losses due to the filter). The output filter was necessary in order to allow the output power to be measured by the power analyser since the output waveforms of a switching converter typically consist of very high speed PWM signals and the bandwidth of a power analyser is insufficient to measure these waveforms directly. The system includes a LISN (line impedance stabilisation network) to be able to measure the common mode and differential mode line current $\left(\mathrm{I}_{\text {line }}\right)$.

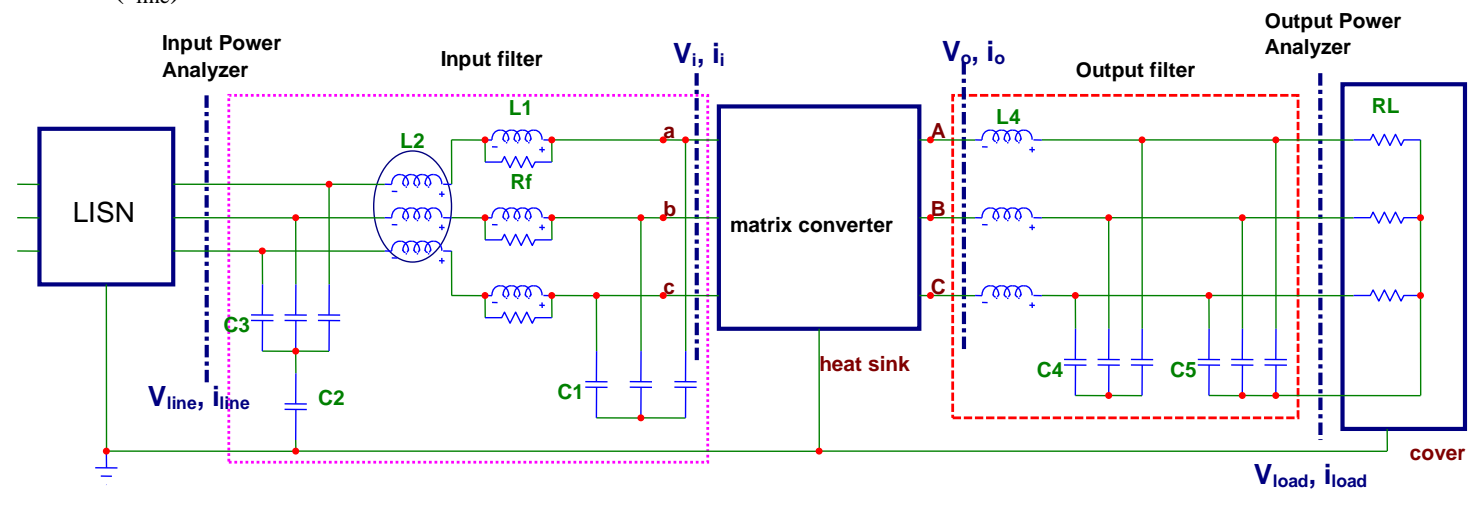

Fig. 2. The system configuration

Table I shows all of the parameters of the input and output filter related passive components together with the load resistor that was used during the testing. Table II shows the main characteristics of the SiC MOSFET and the IGBTs used in the experiment together with the data regarding the gate drive circuit where: $\mathrm{V}_{\text {gate }}$ was the voltage of the power supply of the driver and the 'price ratio' of the switching devices was based on the commercial distributors selling price for small quantities. The SiC MOSFET contained an internal gate resistor of $5[\Omega]$, while this resistor is not present on the Si IGBT. 


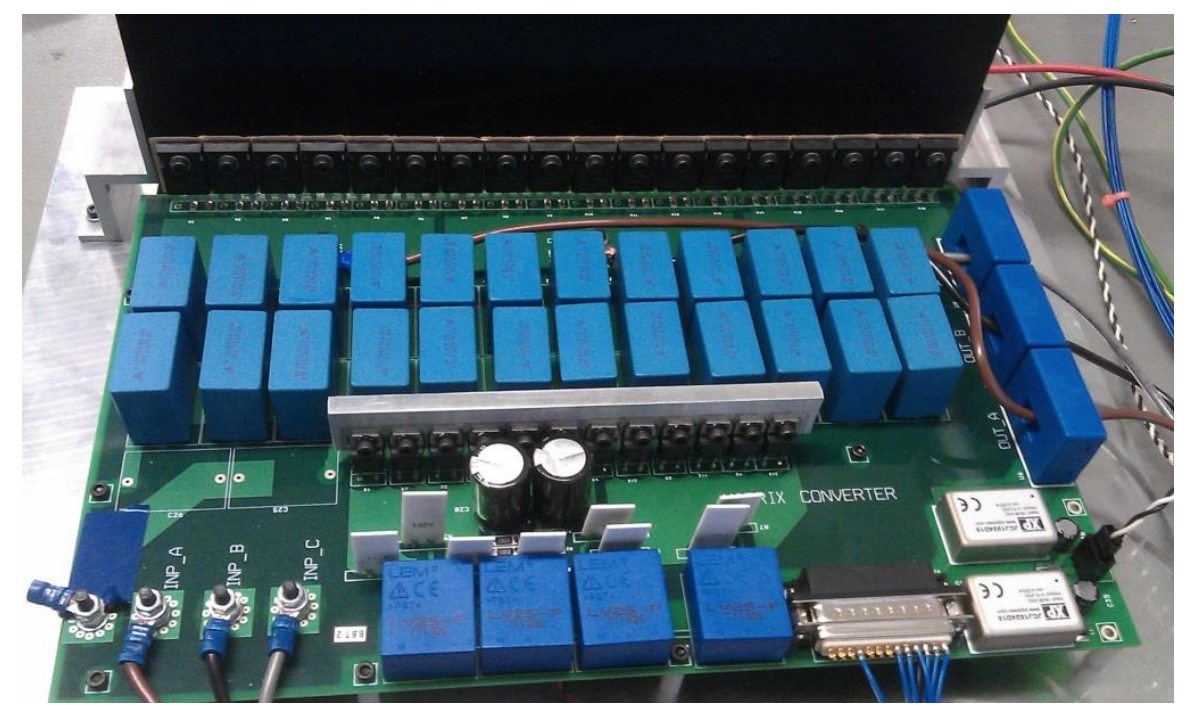

Fig. 3. The prototype

The prototype used to perform the measurements is shown in Figure 3. The 18 devices (TO-247) (from left to right "1" to "18", as shown in figure 1) are clearly visible and mounted on the heat sink. The converter was arranged in this way so as to be able to easily replace the devices and to be able to take thermal data using a thermal camera and as such, all of the devices needed to be in view. The main capacitors of the input filter $\mathrm{C} 1$ (Figure 2) can be seen below the switching devices. The sensors for the input supply are visible at the bottom of the picture while the sensors for the output currents are on the right hand side. The gate drive boards were directly connected to the pin of the devices. The comparison between the two different types of devices ( $\mathrm{Si}$ IGBTs or SiC MOSFETs) was made possible as they are pin-for-pin compatible and they could be simply replaced accordingly.

Table I. The input /output filter

\begin{tabular}{|c|c|c|c|}
\hline Rf & $20[\Omega]$ & C3 & $660[\mathrm{nF}]$ \\
\hline L1 & $145[\mu \mathrm{H}]$ & L4 & $1.2[\mathrm{mH}]$ \\
\hline C1 & $12[\mu \mathrm{F}]$ & C4 & $6[\mu \mathrm{F}]$ \\
\hline L2 & $850[\mu \mathrm{H}]$ & C5 & $4.8[\mu \mathrm{F}]$ \\
\hline C2 & $10[\mu \mathrm{F}]$ & RL & $30-15-10-7.5-4.2[\Omega]$ \\
\hline
\end{tabular}

Table II. The device and gate drive characteristics

\begin{tabular}{|l|c|c|}
\hline & Si IGBT & SiC MOSFET \\
\hline Devices & IKW15T120 & C2CM0080120D \\
\hline Icon at $25^{\circ} \mathrm{C}$ & $30[\mathrm{~A}]$ & $31.6[\mathrm{~A}]$ \\
\hline $\mathrm{V}_{\text {ce }} / \mathrm{V}_{\mathrm{DS}}$ & $1200[\mathrm{~V}]$ & $1200[\mathrm{~V}]$ \\
\hline Price ratio & 1 & 3 \\
\hline & & \\
\hline Vgate & $-12 /+18[\mathrm{~V}]$ & $-8 /+22[\mathrm{~V}]$ \\
\hline Rgate $($ ext.) & $10[\Omega]$ & $1,10,18,75[\Omega]$ \\
\hline Drive & ANCW3190 & ANCW3190 \\
\hline
\end{tabular}

\section{The modulation strategy}

The choice of modulation strategy in combination with the arrangement of the vectors is important when considering switching performance as the switching loss endured by the devices depends on the voltage across and the current flowing through the devices at the time of the commutation and the number of commutations per PWM period. The prototype matrix converter employed one of the most commonly used, symmetrical space vector modulation (SVM) [18-19] methods. The basic equations of the SWM for a three-phase to three-phase matrix converter for the duty cycles of the 4 active vectors are:

$$
d^{I}=\frac{2}{\sqrt{3}} \frac{v_{o}}{v_{i}} \frac{\cos \left(\tilde{\alpha}_{o}-\frac{\pi}{3}\right) \cos \left(\tilde{\beta}_{i}-\frac{\pi}{3}\right)}{\cos \varphi_{i}} \quad d^{I I}=\frac{2}{\sqrt{3}} \frac{v_{o}}{v_{i}} \frac{\cos \left(\tilde{\alpha}_{o}-\frac{\pi}{3}\right) \cos \left(\tilde{\beta}_{i}+\frac{\pi}{3}\right)}{\cos \varphi_{i}}
$$


$d^{I I I}=\frac{2}{\sqrt{3}} \frac{v_{o}}{v_{i}} \frac{\cos \left(\tilde{\alpha}_{o}+\frac{\pi}{3}\right) \cos \left(\tilde{\beta}_{i}-\frac{\pi}{3}\right)}{\cos \varphi_{i}}$

$$
d^{I V}=\frac{2}{\sqrt{3}} \frac{v_{o}}{v_{i}} \frac{\cos \left(\tilde{\alpha}_{o}+\frac{\pi}{3}\right) \cos \left(\tilde{\beta}_{i}+\frac{\pi}{3}\right)}{\cos \varphi_{i}}
$$

and for the null vector:

$d^{0}=1-d^{I}-d^{I I}-d^{I I I}-d^{I V}$

Where: (also represented graphically in figure 4)

$\tilde{\beta}_{i}$ is the angle of the input current vector, with respect to the bisecting line of the corresponding input sector; $\tilde{\alpha}_{o}$ is the angle of the output voltage vector, with respect to the bisecting line of the corresponding output sector; $v_{i}$ is the modulus of the input voltage vector (phase to phase);

$v_{o}$ is the modulus of the output voltage vector (phase to phase)

$\varphi_{i}$ is the angle between the input phase to neutral voltage $\left(\mathrm{e}_{\mathrm{i}}\right)$ and the input current vector

The switching period: $\mathrm{T}_{\mathrm{p}}=1 / \mathrm{F}_{\mathrm{sw}}$ and therefore the timing of the vectors are:

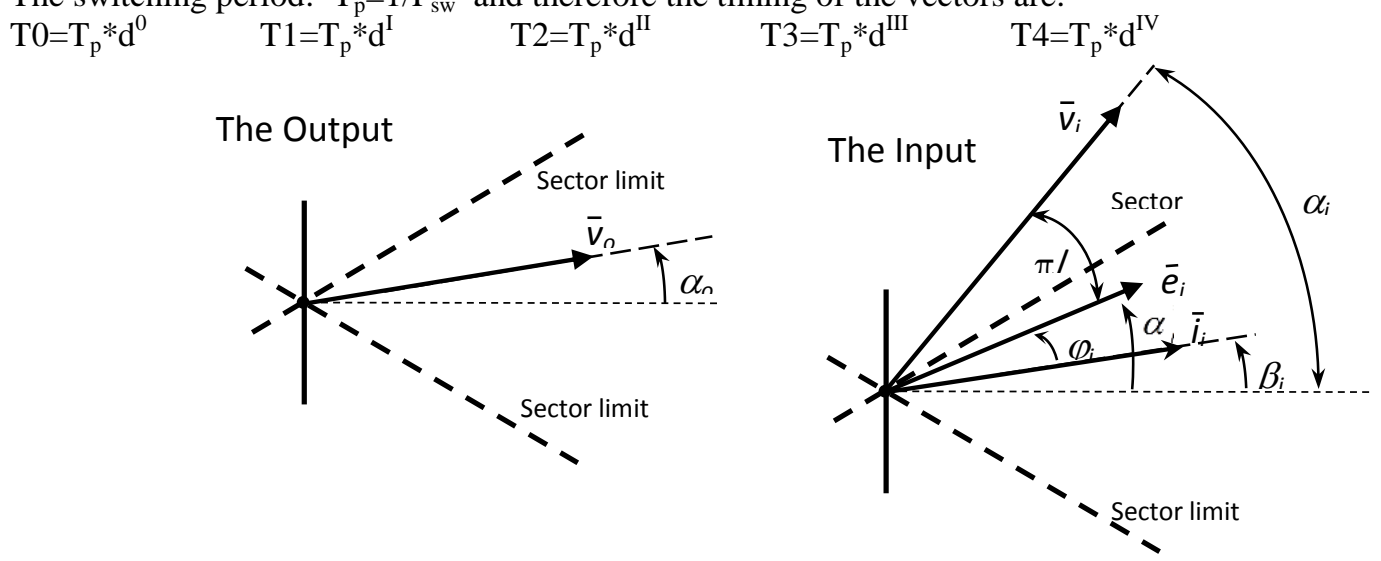

Fig. 4. Output vector and the input vectors in the modulation process

Table III show the switching sequences for a particular input/output sector when using a double-sided symmetrical arrangement of the active vectors and zero vectors, arranged to minimise the number of commutations per period. The red line indicates the point where a commutation occurs. This arrangement results in four commutations for each phase per PWM cycle. The value of $\varphi_{I}$ was set equal to zero for all of the following tests.

Table III. The switching sequences for input current sector $K_{i}=4$ and output voltage sector $K_{V}=1$ showing at which point in the period input phase connected to each output phase

\begin{tabular}{|c|c|c|c|}
\hline \multirow{2}{*}{ Time } & \multicolumn{3}{|c|}{ OUTPUT PHASE } \\
\cline { 2 - 4 } & A & B & c \\
\hline $\mathrm{T} 0 / 8$ & c & c & c \\
\hline $\mathrm{T} 1 / 2$ & c & c & a \\
\hline $\mathrm{T} 3 / 2$ & $\mathrm{c}$ & $\mathrm{a}$ & $\mathrm{a}$ \\
\hline $\mathrm{T} 0 / 4$ & $\mathrm{a}$ & $\mathrm{a}$ & $\mathrm{a}$ \\
\hline $\mathrm{T} 4 / 2$ & $\mathrm{~b}$ & $\mathrm{a}$ & $\mathrm{a}$ \\
\hline $\mathrm{T} 2 / 2$ & $\mathrm{~b}$ & $\mathrm{~b}$ & $\mathrm{a}$ \\
\hline $\mathrm{T} 0 / 4$ & $\mathrm{~b}$ & $\mathrm{~b}$ & $\mathrm{~b}$ \\
\hline $\mathrm{T} 2 / 2$ & $\mathrm{~b}$ & $\mathrm{~b}$ & $\mathrm{a}$ \\
\hline $\mathrm{T} 4 / 2$ & $\mathrm{~b}$ & $\mathrm{a}$ & $\mathrm{a}$ \\
\hline $\mathrm{T} 0 / 4$ & $\mathrm{a}$ & $\mathrm{a}$ & $\mathrm{a}$ \\
\hline $\mathrm{T} 3 / 2$ & $\mathrm{c}$ & $\mathrm{a}$ & $\mathrm{a}$ \\
\hline $\mathrm{T} 1 / 2$ & $\mathrm{c}$ & $\mathrm{c}$ & $\mathrm{a}$ \\
\hline $\mathrm{T} 0 / 8$ & $\mathrm{c}$ & $\mathrm{c}$ & $\mathrm{c}$ \\
\hline
\end{tabular}




\section{4-The switching performance}

In order to safely commutate the inductive load current between the different input phases the 4 step current commutation technique was used [20-21]. Figure 5 shows the commutation sequence used between two bidirectional switches involved in a commutation where $\mathrm{G} 1 \& \mathrm{G} 2$ are the gate drive signals for the forward and reverse devices respectively in the outgoing bi-directional switch and G3 \& G4 are the gate drive signals for the forward and reverse devices respectively for the incoming devices. The path the load current takes through the matrix of bi-directional switches is shown, for the same commutation, in Figure 6.

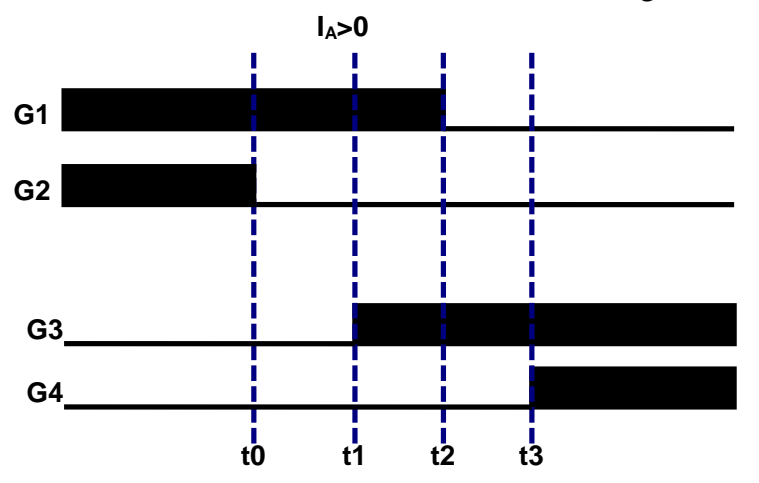

Fig. 5. The sequence of the gate drive for a 4 step current commutation

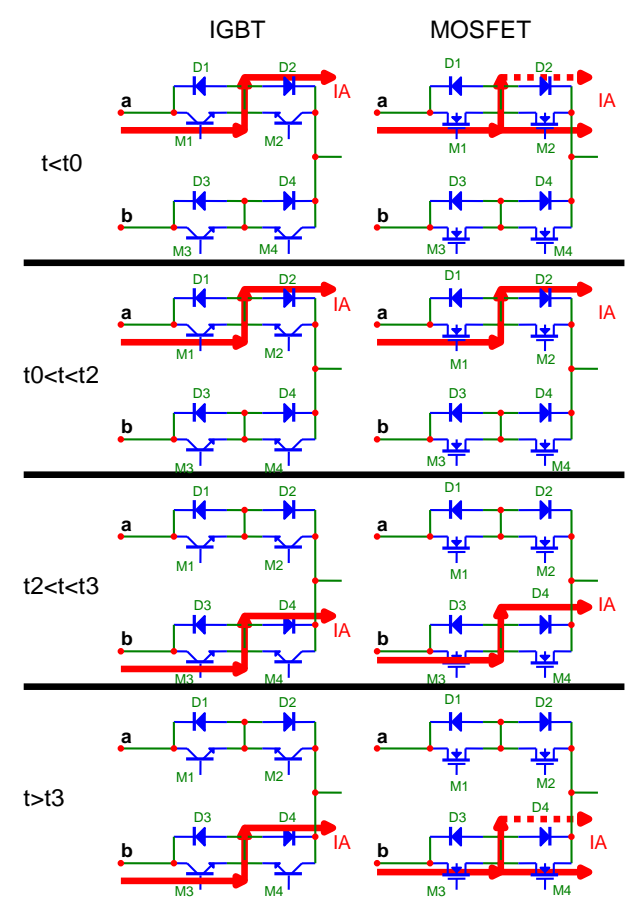

Fig. 6. Current paths for IGBT and MOSFET configurations for the commutation shown in figure 5 and with $\mathrm{Vab}>0$.

When using the 4-step commutation process, in the steady state, both forward and reverse devices are gated. In the case of the Si IGBT based converter, during the steady state, the load current must flow through one IGBT and the associated reverse diode, as shown in Figure $6(\mathrm{t}<\mathrm{t} 0)$. In the case of the SiC MOSFET, the load current can flow in the reverse direction through the MOSFET structure, so the current path can be either through the main MOSFET $\left(\mathrm{R}_{\mathrm{DS}}\right)$ conduction path or through the body diode as indicated by the dashed path in figure 6 . The factors which determine whether or not the body diode is used are the level of current and temperature. If the resistive voltage drop of the main body conduction path is high enough, the current will commutate to the body diode in favour of a lower voltage drop however, during all of the testing of the experimental power 
converter, the body diode never conducted due to the current level used. The body diode of the MOSFET of a bidirectional switch will only conduct the current during a commutation, while one antiparallel diode of the IGBT in the bidirectional switch will conduct also during steady state. For this reason if MOSFETs are used, a two-step or one step commutation strategy [22-23] that during steady state have only one device of the bidirectional switches gated would exhibit higher conduction losses since the reverse conduction through the MOSFET structure would be prevented as it is not gated and the load current would be forced to use the body diode. This can be seen as an advantage in using the 4-step commutation method in that it would result in lower loss in the devices.

The switching performance of the devices varies depending on the type of devices, temperature, gate resistor and power circuit layout (parasitic inductance dependant)[24]. Figure 7 shows the measured performance of the $\mathrm{Si}$ IGBT and the SiC MOSFET during 'turn ON' and 'turn OFF' during normal operation of the matrix converter. In both cases the device observed is device number 18 according to the layout shown in figure 1 .

It can be clearly seen that the SiC MOSFET, as one would expect, is significantly faster than the Si IGBT. The $\mathrm{dV}_{\mathrm{ON}} / \mathrm{dt}$ of the SiC MOSFET is $\approx 11 \mathrm{kV} / \mu$ s and $\mathrm{dV}_{\mathrm{OFF}} / \mathrm{dt} \approx 11 \mathrm{kV} / \mu \mathrm{s}$ while for the IGBT, $\mathrm{dV}_{\mathrm{ON}} / \mathrm{dt} \approx 6.6 \mathrm{kV} / \mu \mathrm{s}$ and $\mathrm{dV}_{\text {OFF }} / \mathrm{dt} \approx 2.7 \mathrm{kV} / \mu$ s however this increase in speed is not as high as one would expect if the data-sheet values are to be assumed. It is also worth noting that both $\mathrm{Si}$ and $\mathrm{SiC}$ devices suffer reverse recovery losses although the $\mathrm{SiC}$ body diode seems to have a lower reverse recovery charge than the Si diode. The situation could be improved for both sets of devices if SiC schottky diodes were used where reverse recovery effects are virtually eliminated. This would imply a simple replacement of the diodes in the case of the Si IGBT but would require the addition of new devices in the case of the SiC MOSFTS since they presently use the body diode of the MOSFET structure. Whilst having faster devices with lower reverse recovery losses in general will reduce the losses, this will conversely affect the electromagnetic interference (EMI) performance of the drive, this issue will be discussed further in section 7 .

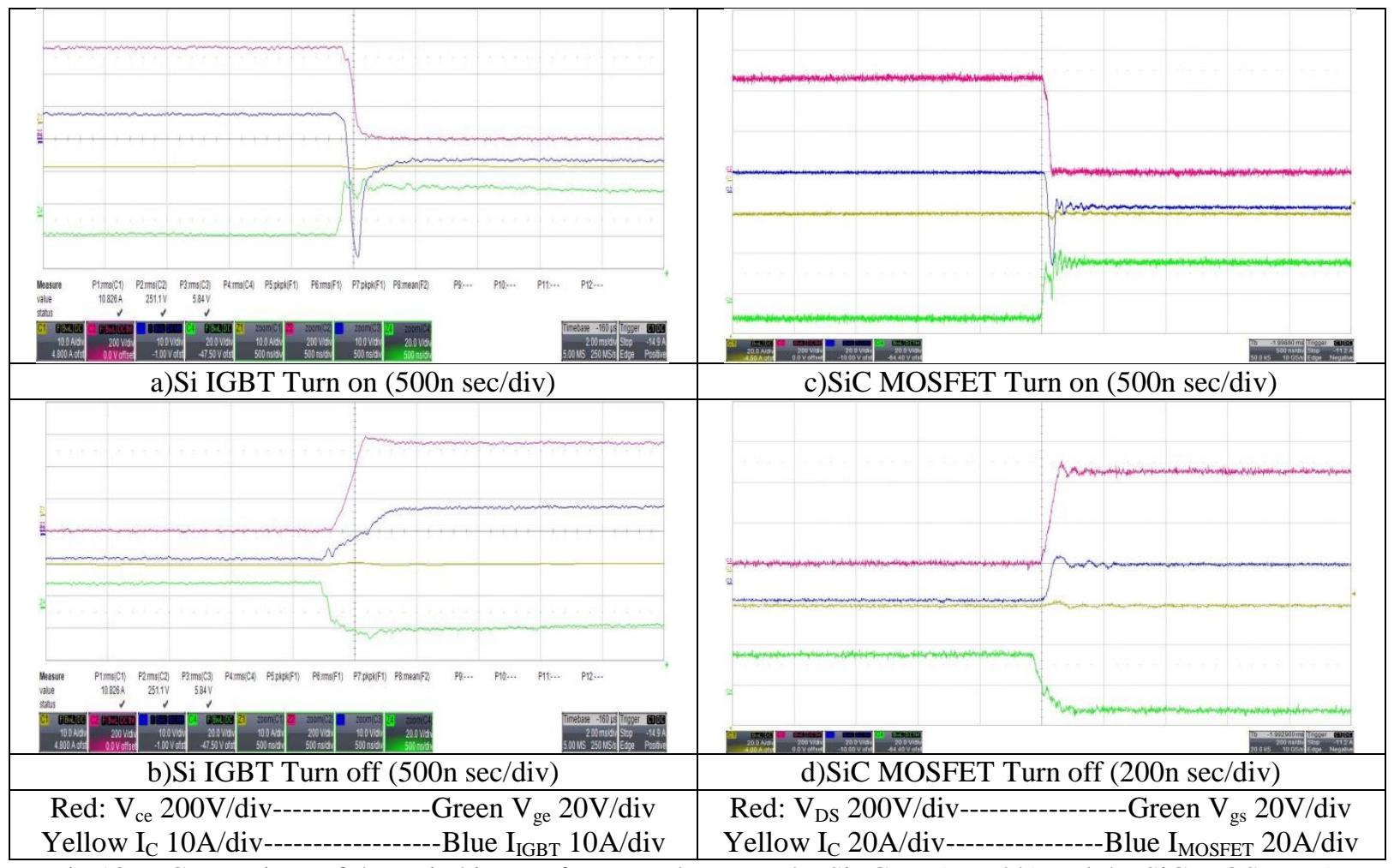

Fig 13-7. Comparison of the switching performance between the Si IGBT (a and b) and the SiC MOSFET (c and d) when using a10 $\Omega$ gate resistor for both cases

\section{5- Efficiency and loss measurements}


The efficiency and loss measurements were performed in order to validate and compare against the theoretical values predicted in section 6 . The analytical loss model of the converter using the two different types of switching devices was then modified and improved using the measured results to take into account factors which are different to those used to determine the datasheet values such as the type of diodes used in the commutation process or the parasitic commutation loop inductance. The efficiency measurements were performed using the two power analyser method according to the arrangement mentioned previously in section 2. This means that the losses of the input (mainly on the inductor L1) and output filter (mainly L4) together with the losses of the four voltage sensors are also included in the loss measurements and needed to be compensated for as a result. To be able to estimate the losses of the power electronic devices of the matrix converter the losses incurred in L1, L4 and voltage sensors were calculated off line.

The loss due to the voltage sensors was measured using the input power analyser when the converter was not switching using the nominal input voltage and resulted in a constant loss of $14 \mathrm{~W}$. The equivalent L-R series combination was measured for inductors (L1, L2 and L4) from $50 \mathrm{~Hz}$ to $150 \mathrm{kHz}$. While the inductor value was very stable in this range of frequencies, the resistance varied significantly, due to the skin effect. For each of the different tests, the inductor currents were measured, and with an offline calculation it was possible to calculate the harmonic currents up to $150 \mathrm{kHz}$. The copper losses of the inductor are defined as:

$$
P_{\text {copper }}=\sum_{n=1}^{n=3 k} R_{n} I_{n, r m s}^{2}=[W]
$$

Knowing all of the current harmonics, the value of the inductor and his physical dimensions (length, weight and cross section) it was possible to calculate the magnetic flux $\left(\varphi_{n}\right)$ and the magnetic field $\left(B_{n}\right)$ for all $n$ frequencies. The material of the inductor that was used was Metglas Powerlight and the data sheet provided the core losses as a function of the frequency and the magnetic field. The core losses are:

$$
P_{\text {core }}=\sum_{n=1}^{n=3 k} 6.5\left(n f_{1(k H z)}\right)^{1.51} B_{n(T)}^{1.74}=\left[\frac{W}{k g}\right]
$$

Other losses such as filter capacitor losses and input filter damping resistor losses were ignored due to the low ESR of the film capacitors and the low power dissipation of the damping resistors $(\mathrm{Rf}<3 \mathrm{~W})$.

Figure 8 shows raw efficiency measurements for three different modulation indexes (ratio of input to output voltage) where no compensation for the filter losses is performed. Although the absolute losses of the switching devices cannot be determined, it is possible to notice a trend in that, as one would expect, the efficiency is reduced as the switching frequency is increased for both the Si IGBT and SiC MOSFET based converters. It can also be seen that the IGBT based converter, when switching at $10 \mathrm{kHz}$, is similar in loss profile to the SiC MOSFET converter when switching at $30 \mathrm{kHz}$.
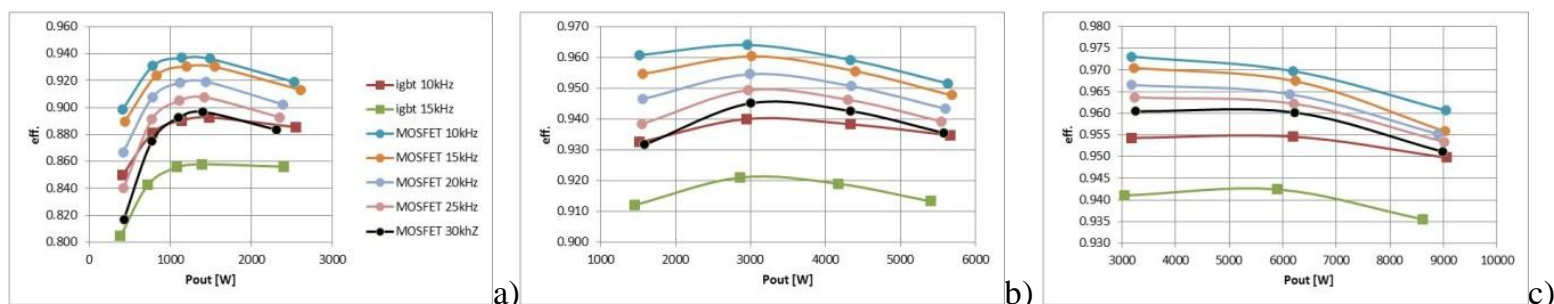

Fig. 8. The efficiency of the converter as a function of the output power for different switching frequencies and different modulation indexes, a) $\mathrm{m}_{\mathrm{i}} \approx 0.25$ b) $\mathrm{m}_{\mathrm{i}} \approx 0.5 \mathrm{c}$ ) $\mathrm{m}_{\mathrm{i}} \approx 0.8$, SiC MOSFETs $[\bullet]$ and IGBTs[

Figure 9 shows the estimates losses of the power electronic devices after having removed the calculated losses of some of the major passive elements of the input/output filter. Again, the IGBT based converter, when switching at $10 \mathrm{kHz}$, is most similar but slightly worse in loss profile to the SiC MOSFET converter when switching at $30 \mathrm{kHz}$. Figure 10 shows the effect on the total losses of the SiC MOSFET converter when using different gate resistor values at different operating points, switching frequencies and modulation indexes, while figure 11 shows the estimated losses of the power devices during the same tests. 

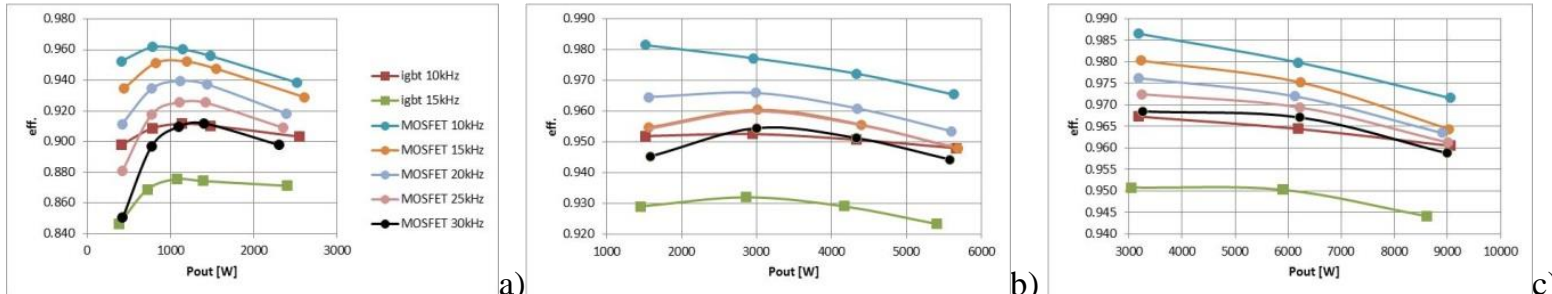

Fig. 9. The calculated efficiency of the power devices as a function of the output power for different switching frequencies and different modulation indexes, a) $\mathrm{m}_{\mathrm{i}} \approx 0.25 \mathrm{~b}$ ) $\mathrm{m}_{\mathrm{i}} \approx 0.5 \mathrm{c}$ ) $\mathrm{m}_{\mathrm{i}} \approx 0.8$, SiC MOSFETs[•] and IGBTs[-]
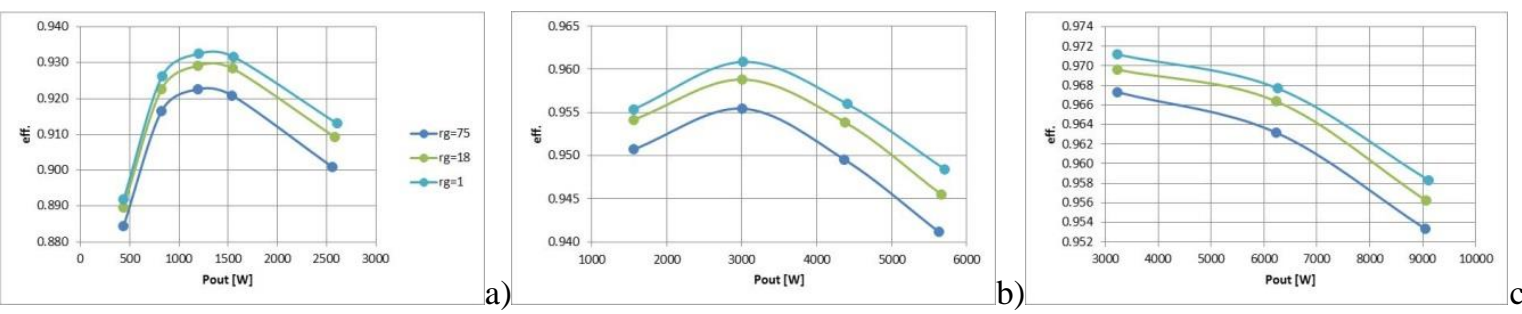

Fig. 10. The efficiency of the converter using $\operatorname{SiC} \operatorname{MOSFETs}[\bullet]$ as a function of the output power for different gate resistor and different modulation index, a) $\left.\mathrm{m}_{\mathrm{i}} \approx 0.25 \mathrm{~b}\right) \mathrm{m}_{\mathrm{i}} \approx 0.5 \mathrm{c}$ ) $\mathrm{m}_{\mathrm{i}} \approx 0.8$
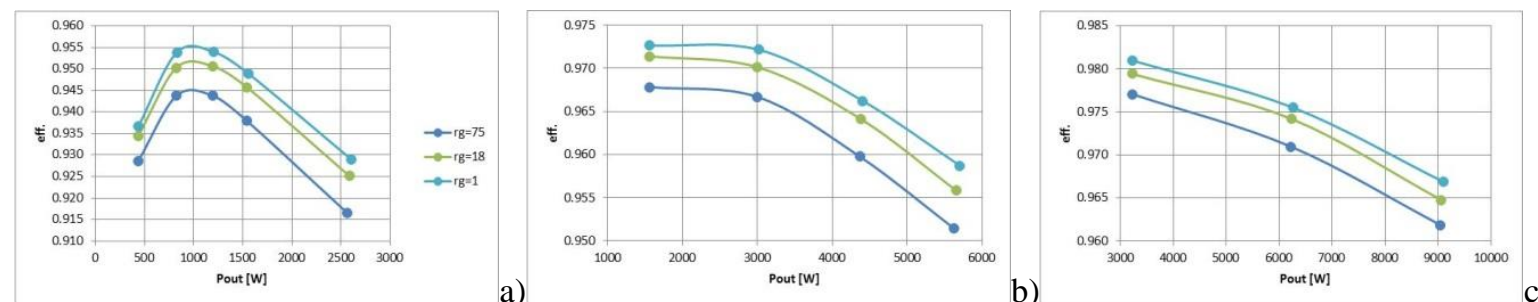

Fig. 11. The efficiency of the power electronics using SiC MOSFETs[ $\bullet$ ] in function of the output power for different gate resistor and different modulation index, a) $\mathrm{m}_{\mathrm{i}} \approx 0.25$ b) $\mathrm{m}_{\mathrm{i}} \approx 0.5$ c) $\mathrm{m}_{\mathrm{i}} \approx 0.8$

Figure 12 show the total losses of the converter for three different output power demanded as function of the switching frequency. Figure 13 show the same test of figure 12 but with the calculated filter losses removed. These results are key to the validation and refinement of the analytical loss models introduced in section 6 as both the conduction loss and switching losses can be extrapolated from these results for the different operating points. As one would expect, based on the switching performance outlined in section 4 , the switching losses (related to the rate of increase of losses with frequency) are lower for the SiC MOSFET based converter when compared to the Si IGBT based converter.
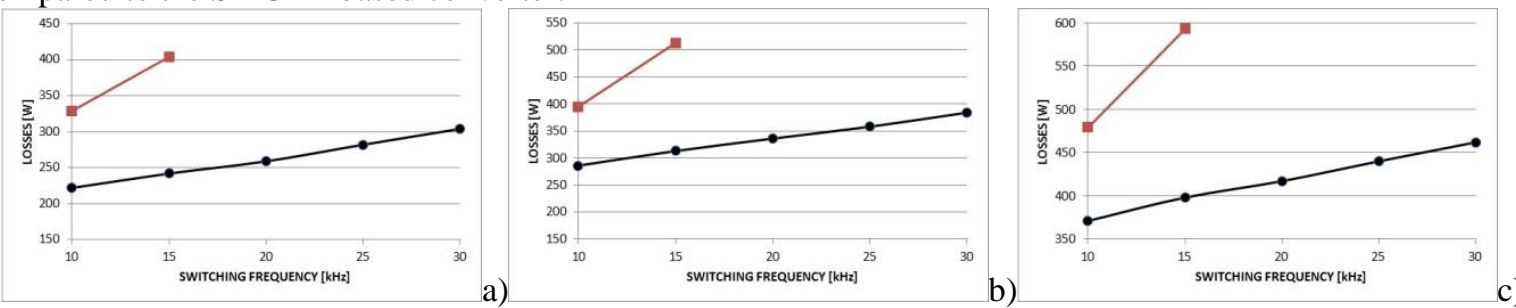

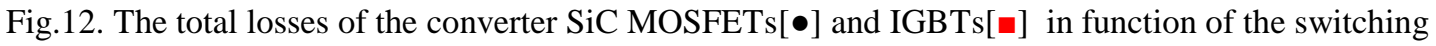
frequency at three different point, a) $\mathrm{m}_{\mathrm{i}} \approx 0.25$ and Pout $\approx 2.5 \mathrm{~kW} \mathrm{~b}$ ) $\mathrm{m}_{\mathrm{i}} \approx 0.5$, Pout $\approx 5.5 \mathrm{~kW} \mathrm{c}$ ) $\mathrm{m}_{\mathrm{i}} \approx 0.8$, Pout $\approx$ $9 \mathrm{~kW}$
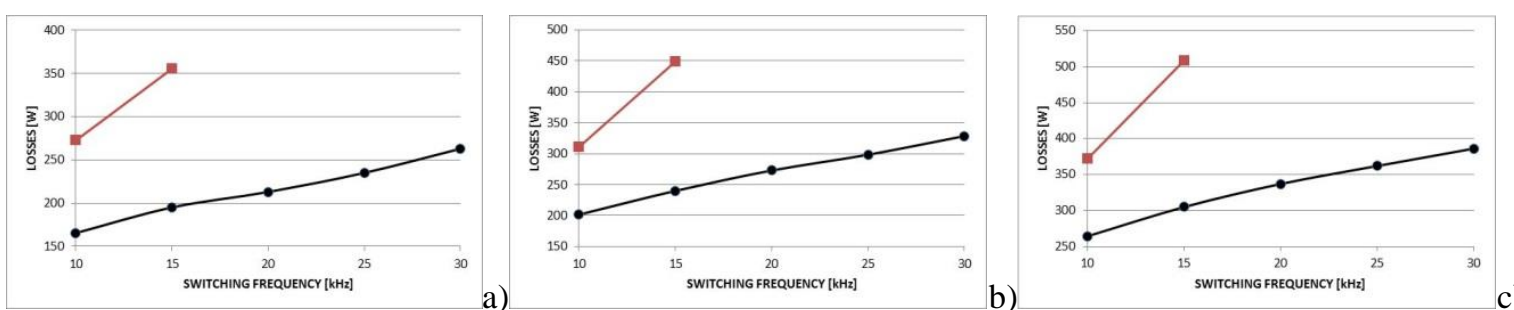

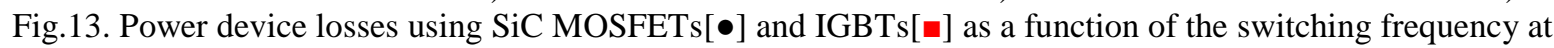
three different points, a) $\mathrm{m}_{\mathrm{i}} \approx 0.25$ and Pout $\left.\approx 2.5 \mathrm{~kW} \mathrm{~b}\right) \mathrm{m}_{\mathrm{i}} \approx 0.5$, Pout $\approx 5.5 \mathrm{~kW} \mathrm{c}$ ) $\mathrm{m}_{\mathrm{i}} \approx 0.8$,Pout $\approx 9 \mathrm{~kW}$ 
Using the system configuration shown in figure 3, it was not possible to increase further the switching frequency of the matrix converter using the Si IGBTs due to heavy losses.

\section{6- The analytical model of the losses}

In order to design and construct power converters, a loss model is often needed in order to determine the physical size and performance requirements of the thermal management system or heat-sink. These loss models are typically based on data-sheet values and are often different, especially where the application operating points are not addressed by the available data. This section will derive a suitable loss model and was then compared against the measured values presented previously in order to refine the loss model.

\subsection{Conduction loss model}

The output current of each phase would go through two devices at all times during both the active and the null vectors. This means that the conducting losses are not function of the modulation index but only of the output current magnitude. In the case of the IGBTs those two devices are one IGBT and one antiparallel diode, while in the case of MOSFETs the output current conducts through two MOSFET $\left(\mathrm{R}_{\mathrm{DS}}\right)$ (see figure 6).

The conducting losses for the IGBT case:

$P_{\text {con_I }}=\frac{3}{\pi} \int_{0}^{\pi} i_{o}\left[V_{C E}\left(i_{o}\right)+V_{F}\left(i_{o}\right)\right] d t$

Where the output current can simply be written in the follow way:

$i_{o}=\sqrt{2} I_{o, R M S} \cos (\omega t)$

$\mathrm{V}_{\mathrm{CE}}$ is also a function of the junction temperature.

The conducting losses for the MOSFETs are given by:

$P_{M}=6 R_{D S} I_{O, R M S}^{2}$

$\mathrm{R}_{\mathrm{DS}}$ is also heavily dependent on the temperature. Figure 14 shows the dependency of the losses of the two power converters with respect to temperature and RMS output current.

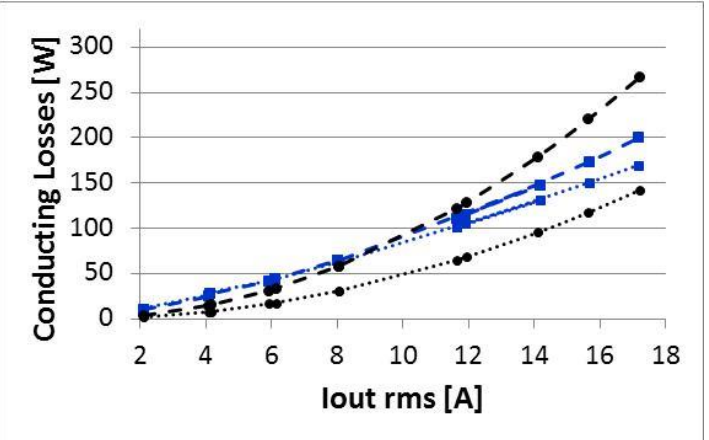

Fig. 14. Conducting losses calculated for the SiC MOSFETs[•] and the Si IGBTs[ロ] for two different temperatures, $25^{\circ} \mathrm{C}$ (.. dotted lines) and $150^{\circ} \mathrm{C}$ (-- dashed lines)in function of the output current

It can be seen in figure 14 that the conduction losses of the Si IGBT based converter are not very dependent with the temperature while in the case of the SiC MOSFET converter, the losses are very temperature dependent. The value of $\mathrm{R}_{\mathrm{DS}}$ increases by $\approx 190 \%$ for temperatures between 25 and $150^{\circ} \mathrm{C}$.

\subsection{Switching loss model}

With reference to Table III, during a complete switching period $\left(\mathrm{T}_{\mathrm{P}}\right)$ there are 12 commutations, four for each output phase. There are two turn ON and two turn OFF situations. In both Si IGBT and SiC MOSFET devices, during the turn ON process, there are also reverse recovery losses from the outgoing diodes (see figure 7).

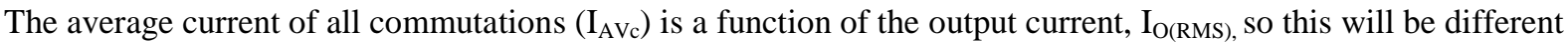
for each test previously outlined, and is equal to: 
$I_{A V C}=\frac{2}{\pi} \int_{0}^{\pi / 2} i_{o} d t=\frac{2 \sqrt{2}}{\pi} I_{o, R M S}$

The average voltage of all commutations $\left(\mathrm{V}_{\mathrm{AVc}}\right)$ was constant during all tests and no power factor compensation was used $\left(\varphi_{\mathrm{i}}=0\right.$ in figure 4$)$ and is equal to:

$V_{A V c}=\frac{3 \sqrt{2} \sqrt{3} V_{i_{r m s}}}{\pi} \int_{0}^{\pi / 3} \cos (\omega t) d t \approx 466[V]$

where: $\mathrm{V}_{\mathrm{i}, \mathrm{rms}}=230 \mathrm{~V}$, (phase to neutral RMS input voltage).

The switching losses can be calculated in the follow way for both Si IGBTs and SiC MOSFETs:

$P_{s w}=3 F_{s w}\left[2 E_{o n}+2 E_{r e c}+2 E_{o f f}\right]$

Where $\mathrm{E}_{\mathrm{on}}$ includes the "tail" and diode reverse recovery for the Si IGBTs and Si Diodes and the body diode reverse recovery for the $\mathrm{SiC}$ MOSFETs. Unfortunately the effects of the diode recovery were not included in the turn on energy of the MOSFETs which may also help to explain the discrepancy between the datasheet values and practical measured values for the SiC MOSFET.

These energy values are given for different temperatures for a given value of voltage and current, so assuming that they are linear with the voltage and current it is possible to scale the energy losses for different voltage and current levels in linear way.

$E=E^{*} \frac{V_{A V C}}{V_{\text {data_sheet }}} \frac{I_{A V C}}{I_{\text {data_sheet }}}$

The switching energy seemed to be proportional and linear while the current above 3A for the IGBT during turn OFF, but this is not the true for the turn ON. Also, the SiC MOSFET turn ON and OFF losses are only proportional above $3 \mathrm{~A}$. For this reason the model implemented this simple condition in order to remain accurate where the current is low:

If $\left(\mathrm{I}_{\mathrm{AVc}}<3\right) \mathrm{I}_{\mathrm{AVc}}=3$

From the data sheets of the Si IGBTs and SiC MOSFETs it is possible to scale the switching energies to a given gate resistor, in our case $\mathrm{Rg}=10 \Omega$.

Table IV. Energy losses of the devices with $\mathrm{Rg}=10 \Omega$

\begin{tabular}{|l|c|c|c|c|}
\hline & \multicolumn{2}{|c|}{ IGBT 600V-15A } & \multicolumn{2}{c|}{ MOSFET 800V-20A } \\
\hline & At $25^{\circ} \mathrm{C}$ & At $150^{\circ} \mathrm{C}$ & At $25^{\circ} \mathrm{C}$ & At $150^{\circ} \mathrm{C}$ \\
\hline$E_{\text {on }}^{*}[\mathrm{~mJ}]$ & 1.02 & 1.6 & 0.549 & 0.524 \\
\hline$E_{\text {rec }}^{*}[\mathrm{~mJ}]$ & 1.14 & 2.0 & 0.132 & 0.132 \\
\hline$E_{\text {off }}^{*}[\mathrm{~mJ}]$ & 1.27 & 2.04 & 0.18 & .233 \\
\hline$E_{\text {TOT }}^{*}[\mathrm{~mJ}]$ & 3.43 & 5.64 & 0.861 & 0.889 \\
\hline
\end{tabular}

When these values are compared with the measured values presented previously, a significant discrepancy can be noted, in particular in the case of the higher speed SiC MOSFET converter. The data sheet values are often measured using optimised single commutation cells which can be difficult to replicate using a practical converter layout. The high dv/dt capability of the devices is degraded by the parasitic inductances of the commutation paths implemented in the PCB power board. Also, the commutation diodes used in data-sheet switching tests are often external devices with unknown recovery but here we use the inbuilt body diode of the MOS structure. It is for this reason that, in this application, it is not possible to use the data sheet commutation energies $\left(\mathrm{E}_{\mathrm{on}}, \mathrm{E}_{\mathrm{rec}}, \mathrm{E}_{\mathrm{off}}\right)$ and hence those reported in table IV will be inaccurate. Also, the temperature does not have a big impact on the switching losses of the SiC MOSFETs while it does affect the IGBTs.

From the measured data shown in figure 13 it is possible to extrapolate the total conduction loss, assuming that they are equal for all switching frequencies, and the switching losses using a liner curve fitting. The losses can be express as a function of the switching frequency:

$P\left(F_{S W}\right)=P_{C O N}^{*}+F_{S W} K^{*}$ 
where: $P_{C O N}^{*}=207 W$, and $K^{*}=6.1 m\left[\frac{W}{H z}\right]$

Assuming that the switching losses can be expressed as in (9), it is possible to extract the total energy losses $\left(\mathrm{E}_{\mathrm{on}}+\mathrm{E}_{\mathrm{rec}}+\mathrm{E}_{\mathrm{off}}\right)$ and the value found from the experimental test is:

$\mathrm{E}_{\text {on }}+\mathrm{E}_{\mathrm{rec}}+\mathrm{E}_{\text {off }}=1.01 \mathrm{~mJ}$ with $\mathrm{V}_{\mathrm{AVc}}=467 \mathrm{~V}$ and $\mathrm{I}_{\mathrm{AVc}}=15 \mathrm{~A}$, this implies that $\mathrm{E}_{\text {on }}+\mathrm{E}_{\mathrm{rec}}+\mathrm{E}_{\text {off }}=2.3 \mathrm{~mJ}$ for $800 \mathrm{~V} / 20 \mathrm{~A}$; This means that the energy loss values to be used in the loss model should be increased by a factor of $2.6(\approx 2.3 \mathrm{~mJ} / 0.889 \mathrm{~mJ})$. It is then possible to apply the same procedure for all of the different tests, and the results of this operation are shown in figure 15. It can be noted that, as mentioned previously, the switching energy is also proportional to the load current but not at low current.

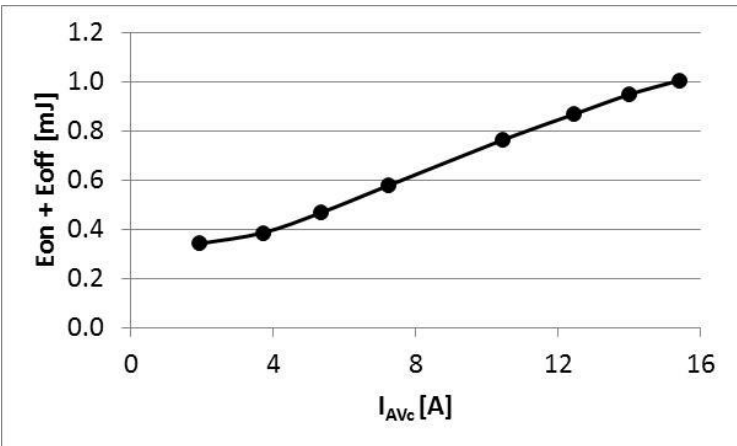

Fig. 15. The commutation energy of the SiC MOSFETs as a function of the average output current (with $\mathrm{Rg}=10 \Omega$ ) based on the experimental results

\subsection{Summary}

It is important to note that the conduction and switching losses are a function of the output current and not of the modulation index and as such it makes sense to show the losses of the converter as a function of the output current. Figure 16 show the estimated losses based on the measured values of the power electronic devices for the Si IGBTs(a) and for the SiC MOSFETs(b) at $10 \mathrm{kHz}$ in combination with the values predicted by the refined analytical model at $25^{\circ} \mathrm{C}$ and $150^{\circ} \mathrm{C}$. It can be seen that this method provides a good correlation between the predicted and measured values.
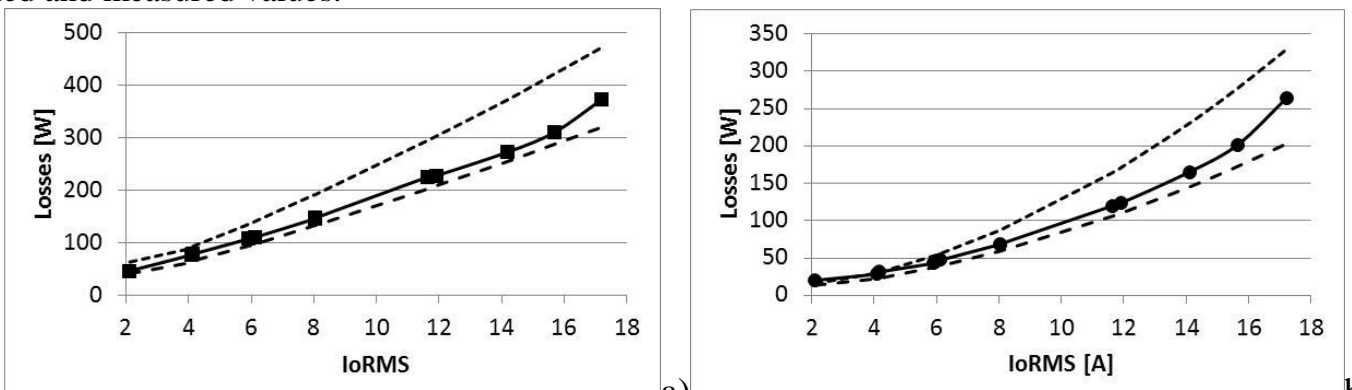

a)

Fig. 16. Comparison of the power electronic losses at $10 \mathrm{kHz}$ in function of the output current against the analytical model at $150{ }^{\circ} \mathrm{C}(.$.$) and 25^{\circ} \mathrm{C}(---)$. a) IGBTs[-],b) MOSFETs[•]

\section{7-impact of switching performance on the quality of the low and EMI frequency input current}

This section will address the impact of the switching performance of both the Si IGBT and SiC MOSFET based power converters for both low frequency power quality issues and electromagnetic interference (EMI) frequencies. Previous work in [25-26] compares the size of EMI filters for different topologies of AC-AC power converters.

\subsection{The low frequency power quality}

The parameters of the input and output filters are given in Table II and were kept constant during the testing. Also, a generic non-optimized filter was used since different switching frequencies were used. Previous work on MC filter optimisation was reported in [27]. Figure 17 shows the line current and voltage for one input phase together with one load voltage when the switching frequency of the matrix converter was equal to $15 \mathrm{kHz}$ for the 
SiC MOSFET based converter. Figure 18 shows the frequency domain spectrum of the line current for different switching frequencies.

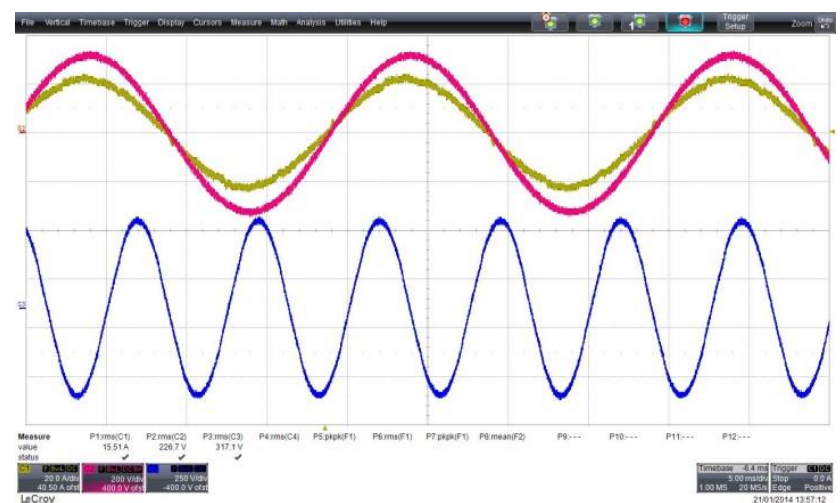

Fig. 17. Line current (yellow, 20A/div), line voltage (red, 200V/div) and load voltage (blue, 250V/div)

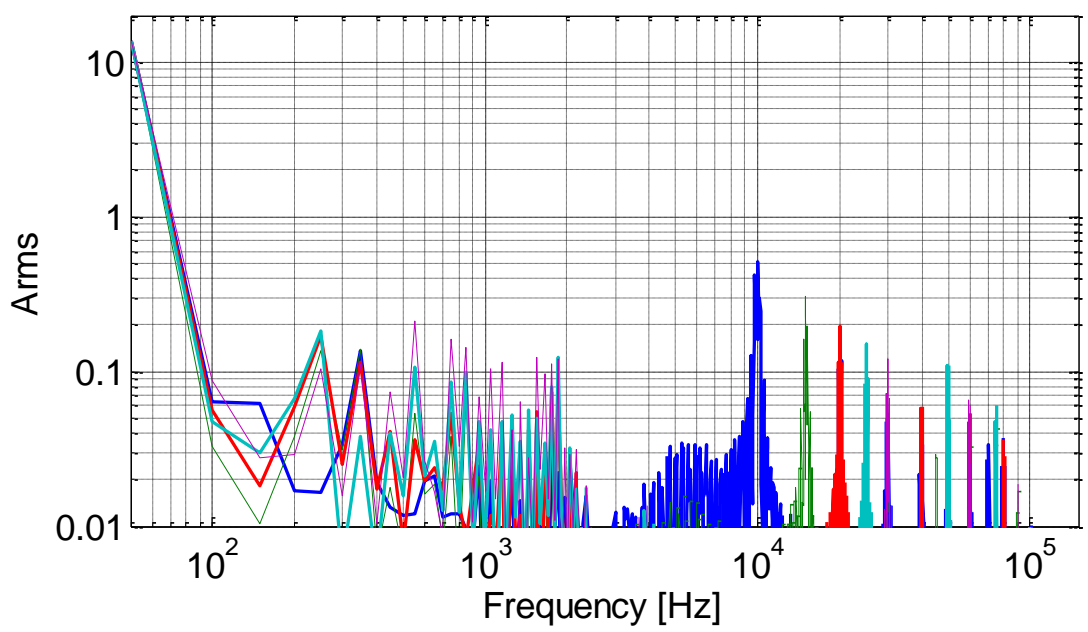

Fig. 18. The spectrum of the line current at different switching frequencies (10kHz(blue), $15 \mathrm{kHz}(\mathrm{green}), 20$ $\mathrm{kHz}($ red) $25 \mathrm{kHz}($ cyan) and $30 \mathrm{kHz}($ magenta))

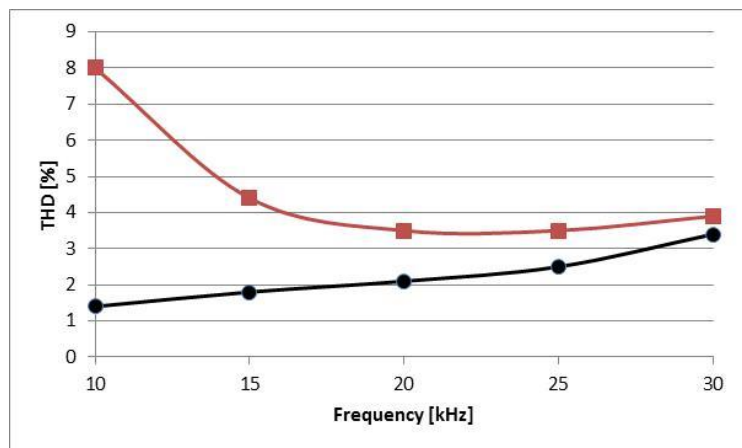

Fig. 19. The THD of the line current in function of the switching frequency [•] calculated up to $2 \mathrm{k}[\mathrm{Hz}]$ and $[\square]$ up to $150 \mathrm{k}[\mathrm{Hz}]$

Figure 19 shows the total harmonic distortion (THD) of the line current for the same test condition of that shown in figure $13 \mathrm{c}$ (MOSFET case). The THD was calculated up to $2 \mathrm{kHz}$ implying that only the first $40^{\text {th }}$ harmonics were considered and also up to $150 \mathrm{kHz}$.

Key considerations:

- The THD measured up to $2 \mathrm{kHz}$ increases with the switching frequency because the gate drive "loses" some pulses which the modulator demands due to the gate drive used (minimum pulse width of 500ns) and as such, more harmonic noise is generated low frequencies

- The impact of the harmonic cluster generated by the switching frequency is reduces with an increasing switching frequency due to the higher attenuation of the input filter 


\subsection{The high frequency performance or EMI}

The performance of a converter at EMI frequencies is very important since a filter is typically needed in order to pass the relevant EMI regulations for connection to the grid. This becomes more important as the switching speed and frequency of the converter increases and as such, particular care should be taken when designing a converter based on devices that have the potential for very high switching speeds. The limits highlighted on the figures below are taken from EN55011 for both class A (industrial) and the lower limits of class B (Domestic) for power converters with less than 20kVA rating.
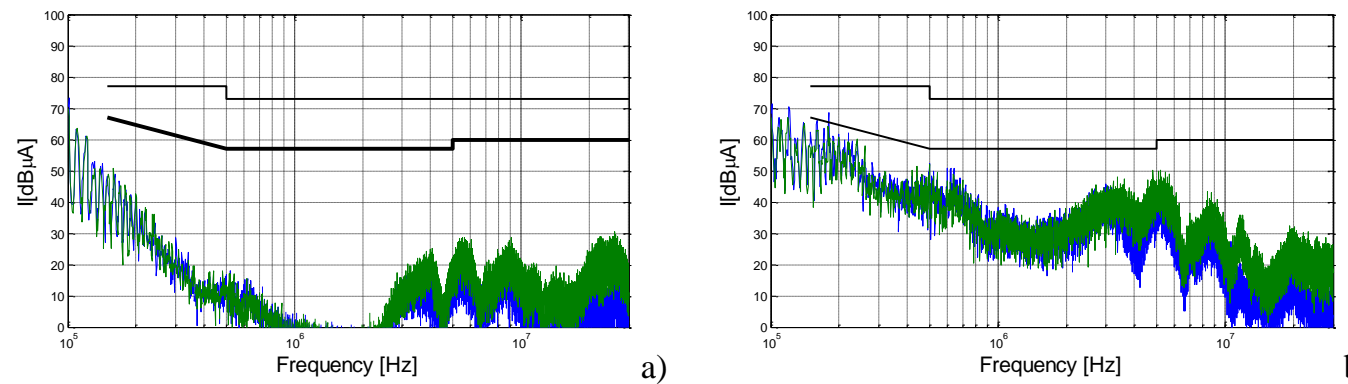

b)

Fig. 20. Comparison of the differential(a) and the common mode (b) current of the $\mathrm{I}_{\text {line }}$ between the Si IGBT (blu) and the SiC MOSFET (green) at $10 \mathrm{kHz}$ switching (10 $\Omega$ gate resistors)

Figure 20 shows a comparison between the SiC MOSFETs and the Si IGBTs when both devices were driven with an external gate resistor of $10 \Omega$, using the same switching frequency $(10 \mathrm{kHz})$ in order to determine the implication of using a device with an increased dv/dt capability. At "low" frequencies $(<2-3 \mathrm{M} \mathrm{Hz})$ there is little or no difference between the Si IGBT and the SiC MOSFETs. Above these frequencies however it is possible to see a significant difference due to the increased dv/dt of the MOSFETs. Figure 21 shows the effect of changing the external gate resistor that was used to drive the SiC MOSFETs. At "low" frequency $(<5 \mathrm{MHz})$ there is little difference while at higher frequencies it is possible to see an increased EMI amplitude due to the much faster $\mathrm{dv} / \mathrm{dt}$ generated by reducing the gate resistor. Clearly, an increase in gate resistance will result in a slower device and an improved EMI spectrum but conversely, this will also increase the switching losses as described previously and a compromise will need to be found based on the specific application requirements. Figure 22 shows the effect of varying the main switching frequency of a matrix converter. In this example, the $\mathrm{SiC}$ MOSFET converter was used with an external gate resistor of $10 \Omega$. It can be seen that increasing the switching frequency create some problems in the EMI spectrum, especially for the common mode current.
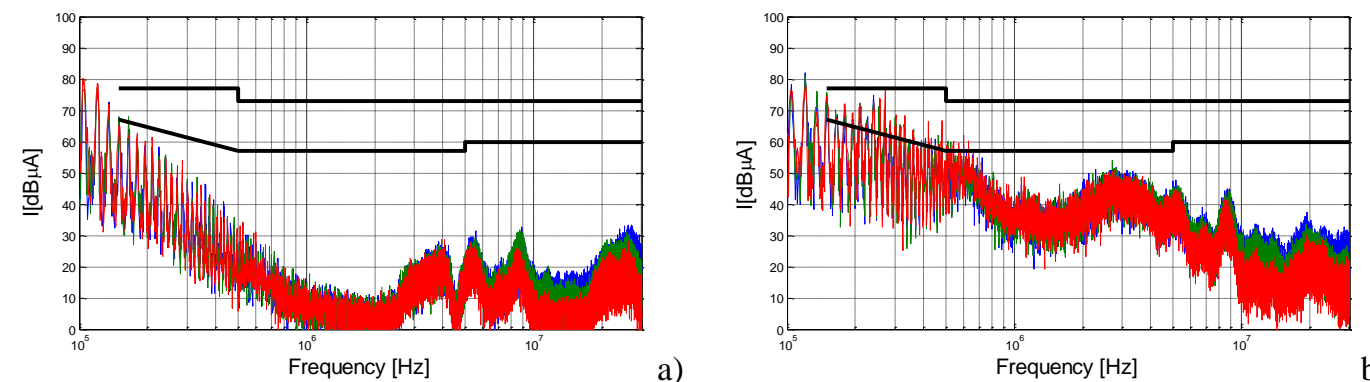

Fig. 21. Comparison of the differential (a) and the common mode (b) of $\mathrm{I}_{\text {line. }}$. With a switching frequency of $15 \mathrm{k}[\mathrm{Hz}]$, using SiC MOSFETs with three different $\mathrm{R}_{\mathrm{g}}=1,18,75[\Omega]$
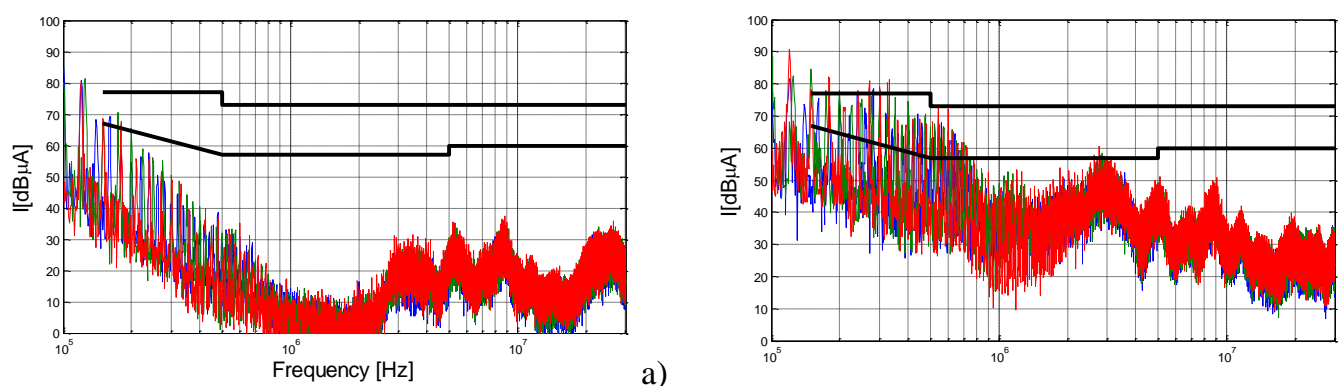

Fig. 22 Comparison of the differential (a) and the common mode (b) of $\mathrm{I}_{\text {line. With }} \mathrm{R}_{\mathrm{g}}=10[\Omega]$, for three different switching frequency:20k,25k,30k [Hz] 
Using the filter parameters defined in table II, the differential mode line current is almost inside the desired limit, even at $30 \mathrm{kHz}$, while the common mode is outside of the limit for switching frequencies greater than 10 $\mathrm{kHz}$. It seems clear that if the converter is to be used at a higher switching frequency $(>10 \mathrm{kHz})$ it will need different filter parameters and potentially, a different filter configuration.

Considering that the original filter that was used gave a good result for the line current THD, there were some problems in the EMI area, especially for the common mode, and as such, it needed to be improved. There are basically two solutions to this problem:

- Increase the value of the filter parameters to get a larger attenuation at $150 \mathrm{kHz}$, but in this way the filter would also become larger,

- Design a two stage input filter that would be smaller due to a reduction in energy storage requirements. Figure 23 shows the schematic diagram of the new double stage EMI filter. The specifications of this new filter are:

- Differential mode: it should have the same or lower attenuation for all frequency greater than the switching frequency $(30 \mathrm{kHz})$

- Common mode: it must have a greater attenuation above $150 \mathrm{kHz}$

Considering that the "original" filter exhibited a good damping, the ratio (C/L) was kept almost constant for the differential mode. With this consideration the new filter is show in figure 23 and the parameters are show in table V.

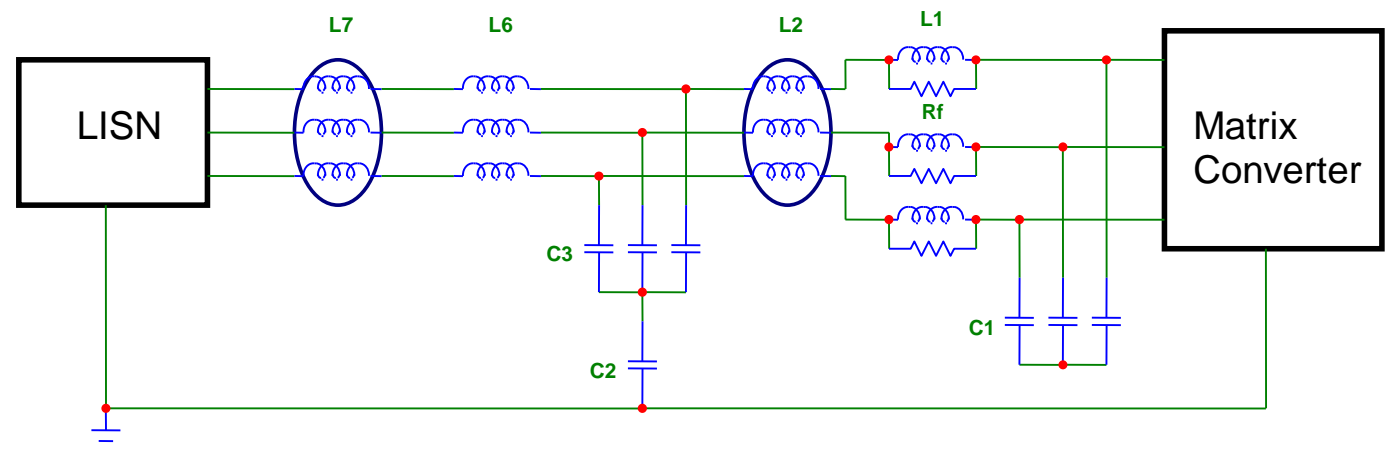

Fig. 23. The new double stage input filter for combined low frequency power quality and EMI attenuation

Table V. The parameters of the new input filter

\begin{tabular}{|c|c|c|c|}
\hline Rf & $15[\Omega]$ & C2 & $4.5[\mu \mathrm{F}]$ \\
\hline L1 & $68[\mu \mathrm{H}]$ & C3 & $3[\mu \mathrm{F}]$ \\
\hline C1 & $6[\mu \mathrm{F}]$ & L6 & $29[\mu \mathrm{H}]$ \\
\hline L2 & $450[\mu \mathrm{H}]$ & L7 & $250[\mu \mathrm{H}]$ \\
\hline
\end{tabular}
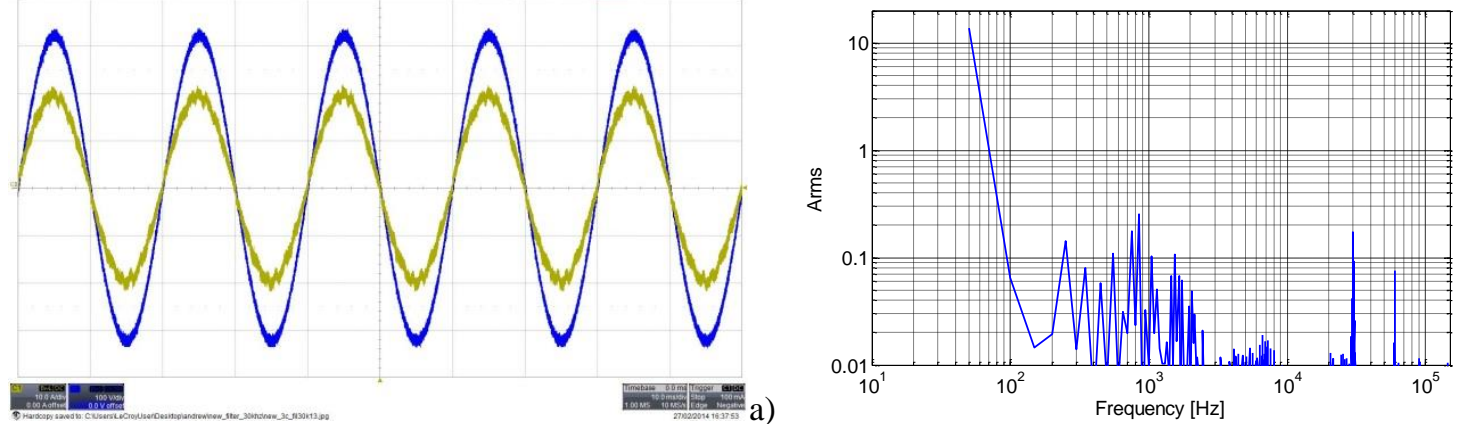

Fig. 24. a) $I_{\text {line }}(10 \mathrm{~A} /$ div $) V_{\text {line }}(100 \mathrm{~V} /$ div $)$ b) Spectrum of the $I_{\text {line }}$, at $30 \mathrm{k}[\mathrm{Hz}]$ and $9 k[W]$.

The THD of $\mathrm{I}_{\text {line }}$ with this new input filter (see figure 23) is $4.1 \%$ calculated up to $150 \mathrm{kHz}$ and $3.1 \%$ up to $2 \mathrm{kHz}$. The small difference with the previous filer is due to a very small attenuation difference around $30 \mathrm{k}[\mathrm{Hz}]$. 

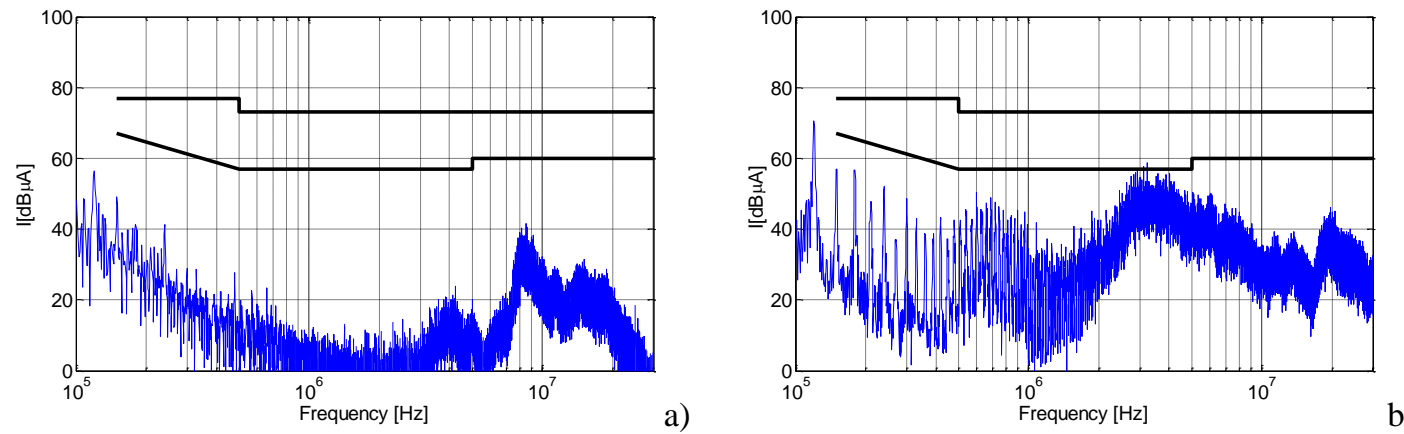

Fig. 25. The differential (a) and the common mode (b) of $\mathrm{I}_{\text {line }}$ with a new input filter at $30 \mathrm{k}[\mathrm{Hz}]$

Figure 25 shows the results of the line current measurements at EMI frequencies when the matrix converter was switching at $30 \mathrm{kHz}$ using the new input filter. The differential mode is now superior to the original filter design and the common mode now is now inside the limit.

The main focus of this paper is on the comparison of the type of switching devices used and not about the input filter of a matrix converter. These results have shown that the main difference between the Si IGBT and the SiC MOSFETs on the EMI spectrum in terms of meeting the desired limits is due to the switching frequency of the converter and that the speed (dv/dt) of the devices only affects the higher frequencies where the EMI filter has a greater attenuation.

\section{Conclusions}

This paper presents an experimental comparison of Si IGBTs and SiC MOSFETs used in a direct matrix converter based on efficiency and EMI measurements. The paper shows the influence of the gate resistor on the converter losses and also on the EMI spectrum generated. The use of the faster SiC MOSFETs improves the efficiency of converter. A similar efficiency is achieved when the Si IGBT based converter and the SiC MOSFET based converter switch at $10 \mathrm{kHz}$ and $30 \mathrm{kHz}$ respectively. The paper shows, using experimental data, that it is not possible to achieve the switching losses defined within the SiC MOSFET data sheet due to the distance between the switches and parasitic commutation loop inductance present in the converter layout. This implies that with a well-designed, fully integrated power module that minimizes the commutation loop inductance between bi-directional switches it should be possible to improve further the efficiency of a matrix converter using the SiC MOSFETs. Due to the lower switching losses of the SiC MOSFET it is possible to reduce the size of the heat sink or increase the switching frequency and reduce the size of the input filter.

This paper also presents a simple but effective analytical model to calculate the losses of converter for the $\mathrm{Si}$ IGBT and for the SiC MOSFET based converters using both data-sheet values together with circuit layout dependant modification factors based on measurements. EMI measurement and analysis presented in this paper has shown that the switching frequency has a greater effect on input filter design than the high frequency $\mathrm{dv} / \mathrm{dt}$ related effects and as such, a methodology for the design and validation of an alternative filter was also presented.

\section{References}

[1] Empringham, L., Kolar, J.W., Rodriguez, J., Wheeler, P.W., Clare, J.C., "Technological Issues and Industrial Application of Matrix Converters: A Review", Industrial Electronics, IEEE Transactions on, Volume: 60 , Issue: 10 , Publication Year: 2013, Page(s): 4260 - 4271

[2] Levi, E. ; Bodo, N. ; Dordevic, O. ; Jones, M., "Recent advances in power electronic converter control for multiphase drive systems", Electrical Machines Design Control and Diagnosis (WEMDCD), 2013 IEEE Workshop on, 2013 , Page(s): 158- 167

[3] El-Khoury, C.N. ; Kanaan, H.Y. ; Mougharbel, I. ; “Al-Haddad, K., A review of matrix converters applied to PMSG based wind energy conversion systems", Industrial Electronics Society, IECON 2013 - 39th Annual Conference of the IEEE, Page(s): 7784- 7789

[4] Mei Su ; Hui Wang; Yao Sun ; Jian Yang; Wenjing Xiong ; Yonglu Liu, "AC/DC Matrix Converter With an Optimized Modulation Strategy for V2G Applications", Power Electronics, IEEE Transactions on, Volume: 28 , Issue: 12, 2013 , Page(s): 5736 - 5745 
[5] Khwan-on, S. ; de Lillo, L. ; Empringham, L. ; Wheeler, P., "Fault-Tolerant Matrix Converter Motor Drives With Fault Detection of Open Switch Faults", Industrial Electronics, IEEE Transactions on Volume: 59 , Issue: 1, 2012 , Page(s): $257-268$

[6] Xiong Liu ; Poh Chiang Loh ; Peng Wang; Blaabjerg, F., "A compact versatile matrix converter to integrate various energy resources to utility network", Energy Conversion Congress and Exposition (ECCE), 2011 IEEE, Page(s): $238-245$

[7]Kolar, J.W. ; Friedli, T. ; Krismer, F. ; Round, S.D. “ The essence of three-phase AC/AC converter systems”, Power Electronics and Motion Control Conference, 2008, EPE-PEMC 2008. 13 ${ }^{\text {th }}, 2008$, Page(s): $27-42$

[8]Bernet, S., Ponnaluri, S., Teichmann, R., "Design and loss comparison of matrix converters, and voltagesource converters for modern AC drives", Industrial Electronics, IEEE Transactions On, Volume: 49 , Issue:2, Publication Year: 2002 , Page(s): 304 - 31

[9] Apap, M., Clare, J.C., Wheeler, Pw., Bland, M., Bradley, K., "Comparison of losses in matrix converters and voltage source inverters", Matrix Converters, IEE Seminar on (Digest No. 2003/10100), Publication Year: 2003, Page(s): 4/1 - 4/6

[10] Xiaoyan Huang ; Goodman, A. ; Gerada, C. ; Youtong Fang ; Qinfen Lu, "A Single Sided Matrix Converter Drive for a Brushless DC Motor in Aerospace Applications", Industrial Electronics, IEEE Transactions on, Volume: 59, Issue: 9, 2012 , Page(s): 3542 - 3552

[11] Empringham, L. ; De Lillo, L. ; Khwan-On, S. ; Brunson, C. ; Wheeler, Pw. ; Clare, J.C, “ Enabling technologies for matrix converters in aerospace applications", Compatibility and Power Electronics (CPE), 2011 7th International Conference-Workshop, 2011, Page(s): 451- 456

[12]Galea, M. ; Buticchi, G. ; Empringham, L. ; de Lillo, L. ; Gerada, C., “ Design of a High Force Density Tubular Motor", Industry Applications, IEEE Transactions on, Issue: 99, 2014 , Page(s): 1

[13]Lopez Arevalo, S., Zanchetta, P., Wheeler, P.W., Trentin, A., Empringham, L., "Control and Implementation of a Matrix-Converter-Based AC Ground Power-Supply Unit for Aircraft Servicing”, Industrial Electronics, IEEE Transactions on, Volume: 57 , Issue: 6, 2010, Page(s): 2076 - 2084

[14] Empringham, L., Wheeler, P., Clare, J., "Power density improvement and robust commutation for a 100 kW Si-SiC matrix converter", Power Electronics and Applications, 2009. EPE '09. 13th European Conference on, 2009, Page(s): 1 - 8About comparison between IGBT and SiC mosfet

[15]Empringham, L. ; de Lillo, L. ; Wheeler, P. ; Clare, J., "Calorimetric comparison of the use of Silicon Carbide diodes in a $100 \mathrm{~kW}$ matrix converter for aerospace applications", Power Electronics and Applications (EPE 2011), Proceedings of the 2011-14th European Conference on, 2011, Page(s): 1-7

[16] Empringham, L., de Lillo, L., Schulz, M.," Design Challenges in the Use of Silicon Carbide JFETs in Matrix Converter Applications", Power Electronics, IEEE Transactions on, Volume: 29, Issue: 5, Publication Year: 2014 , Page(s): 2563 - 2573

[17]Oswald, N. ; Anthony, P. ; McNeill, N. ; Stark, B.H., " An Experimental Investigation of the Tradeoff between Switching Losses and EMI Generation With Hard-Switched All-Si, Si-SiC, and All-SiC Device Combinations", Power Electronics, IEEE Transactions on,Volume: 29 , Issue: 5, 2014 , Page(s): 2393 - 2407

[18] Huber, L., Borojevic, D., "Space vector modulated three-phase to three phase matrix converter with input power factor correction", Industry Applications, IEEE Transactions on, Volume: 31 , Issue: 6, Publication Year: 1995, Page(s): 1234 - 1246

[19] Casadei, D., Serra, G., Tani, A., Zarri, L., "Matrix converter modulation strategies: a new general approach based on space-vector representation of the switch state", Industrial Electronics, IEEE Transactions on, Volume: 49 , Issue: 2, 2002, Page(s): 370 - 381

[20]Burany N; 'Safe control of four quadrant switches', IAS Annual meeting, pp.1190-1194, 1989.

[21]D. Casadei; A. Trentin; M. Matteini; M. Calvini, "Matrix converter commutation strategy using both output current and input voltage sign measurement", EPE2003-PP1101

[22] Ziegler M. and Hofmann W., "Semi Natural Two Steps Commutation Strategy for Matrix Converters", IEEE PESC Conference Record, pp. 727-731, 1998.

[23] Mazet L., Boulant H., Huselstein J.J. and Glaize C., "Switching Control in Three-Phase Matrix Converter by Discrimination of Command Orders”, PEMC Conference Record, vol. 2, pp.64-67, 1998. 
[24]Trentin, A., Zanchetta, P. Wheeler, P., Clare, J., "Performance evaluation of high-voltage $1.2 \mathrm{kV}$ silicon carbide metal oxide semi-conductor field effect transistors for three-phase buck-type PWM rectifiers in aircraft applications", Power Electronics, IET, Volume: 5 , Issue: 9, 2012, Page(s): 1873 - 1881

[25] Bo Wen, Xuning Zhang, Qiong Wang, Burgos, R., Mattavelli, P., Boroyevich, D., "Comparison of threephase ac-ac matrix converter and voltage dc-link back-to-back converter topologies based on EMI filter", Energy Conversion Congress and Exposition (ECCE), 2013 IEEE, 2013, Page(s): 2698 - 2706

[26] Heldwein, M.L., Kolar, J.W., "Impact of EMC Filters on the Power Density of Modern Three-Phase PWM Converters", Power Electronics, IEEE Transactions on, Volume: 24, Publication Year: 2009, Page(s): 1577 1588

[27] Trentin, A., Zanchetta, P., Clare, J., Wheeler, P., “Automated Optimal Design of Input Filters for Direct AC/AC Matrix Converters”, Industrial Electronics, IEEE Transactions on, Volume: 59, Issue: 7, Publication Year: 2012, Page(s): 2811 - 2823 